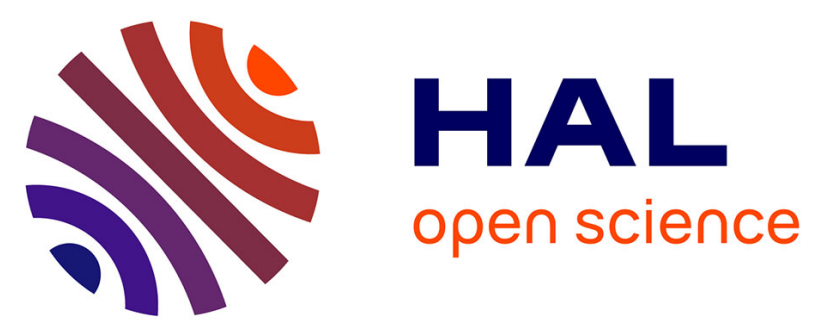

\title{
Estimating microbial populations by flow cytometry: Comparison between instruments
}

\author{
Catherine Gérikas Ribeiro, Dominique Marie, Adriana Lopes dos Santos, \\ Frederico Pereira Brandini, Daniel Vaulot
}

\section{- To cite this version:}

Catherine Gérikas Ribeiro, Dominique Marie, Adriana Lopes dos Santos, Frederico Pereira Brandini, Daniel Vaulot. Estimating microbial populations by flow cytometry: Comparison between instruments. Limnology and Oceanography: Methods, 2017, 14 (11), pp.750 - 758. 10.1002/lom3.10135 . hal-01482199

\section{HAL Id: hal-01482199 \\ https://hal.sorbonne-universite.fr/hal-01482199}

Submitted on 7 Mar 2017

HAL is a multi-disciplinary open access archive for the deposit and dissemination of scientific research documents, whether they are published or not. The documents may come from teaching and research institutions in France or abroad, or from public or private research centers.
L'archive ouverte pluridisciplinaire HAL, est destinée au dépôt et à la diffusion de documents scientifiques de niveau recherche, publiés ou non, émanant des établissements d'enseignement et de recherche français ou étrangers, des laboratoires publics ou privés. 
1 Estimating microbial populations by flow cytometry: comparison between instruments

2

3 Catherine Gérikas Ribeiro ${ }^{1 *}$, Dominique Marie $^{2}$, Adriana Lopes dos Santos ${ }^{2}$, Frederico Pereira 4 Brandini ${ }^{1}$, Daniel Vaulot ${ }^{2}$.

5

$6{ }^{1}$ Departamento de Oceanografia Biológica, Instituto Oceanográfico, Universidade de São Paulo, São $7 \quad$ Paulo, Brasil

$8 \quad{ }^{2}$ Sorbonne Universités, UPMC Univ Paris 06, CNRS, UMR 7144, Station Biologique, Place Georges

9 Teissier, 29680 Roscoff, France

$12 *$ Corresponding author

13 E-mail: catherine.gerikas@gmail.com (CGR)

14

15 Running head: Estimating microbial populations by FCM

16 Keywords: flow cytometry; microbial oceanography; heterotrophic bacteria; picoplankton; 17 nanoplankton. 
Abstract

For almost 3 decades, flow cytometry has allowed researchers to investigate ocean planktonic communities using size and cell fluorescence properties. However, oceanographic applications must face two constraints. First, when dealing with marine microbes, instruments must be sensitive because these organisms are very small and with low fluorescence. Second, instruments must be portable to be used on board ships. We compared the performance of two instruments, the BD FACSCanto ${ }^{\mathrm{TM}}$ and BD Accuri $^{\mathrm{TM}}$ C6. The former is an expensive laboratory-based instrument which has a very good sensitivity, whilst the latter is less sensitive but presents critical advantages for field studies (easy handling and transportation, relatively low cost). We have analyzed 102 samples from the South Atlantic Ocean from 3 transects off Brazil, within the euphotic zone. We compared cell abundance of heterotrophic bacteria, Prochlorococcus and Synechococcus, as well as photosynthetic pico- and nanoeukaryotes. Heterotrophic bacteria, pico- and nano-eukaryotes could be easily detected with both cytometers. Prochlorococcus and Synechococcus populations were severely under-estimated with the BD Accuri' ${ }^{\mathrm{TM}}$ C6, particularly for samples from the well-lit layers of the water column. Correction of abundance data using previously suggested approaches was not sufficient to fully compensate for the

34 low sensibility. Our data suggest that the BD Accuri ${ }^{\mathrm{TM}}$ C6 is suitable for counting marine bacteria and photosynthetic eukaryotes, but not Prochlorococcus and Synechococcus. 


\section{Introduction}

Flow cytometry (FCM) is a well-established technique (Marie et al. 1997; Gasol and del Giorgio 2000) used since the 1980s (Trask et al. 1982; Olson et al. 1985) for enumeration and characterization of marine micro-organisms. FCM analysis of planktonic communities fulfills the scientific demands of rapid and accurate cell counting, as it considerably reduces the bias introduced by visual counting (Marie et al. 2005). By simultaneously recording several parameters during analysis, FCM allows the discrimination of pico- and nanoplankton populations and the estimation of their abundance, cell size, and pigment content (Marie et al. 2005), both by natural (chlorophyll, phycoerythrin) or induced (fluorescent dyes) fluorescence (Marie et al. 1997).

The flow cytometer registers events as cells are aligned in a fluid stream and flow through a beam of focused light usually provided by one or several lasers. For each particle, scattered light and emitted fluorescence are converted to digital signals and recorded. A flow cytometer comprises three main systems: fluidics (particle transport), optics (laser beam and optical filters), and electronics (signal conversion into electronic data). Detectors for scattered light located at $180^{\circ}$ and $90^{\circ}$ from the light source are called forward scatter (FSC) and side scatter (SSC), respectively. Fluorescence at different wavelengths (typically green, orange and red) is also recorded. Signals associated with each parameter are displayed as cytograms, which are used to discriminate and count different populations based on scattering and fluorescence features. Phytoplankton populations can be differentiated by FCM according to specific values of the recorded parameters (FSC, SSC, red or orange fluorescence).

Bacteria are in general detected after staining with a nucleic acid strain such as SYBR Green-I (Marie et al. 1997). Two different groups can be distinguished based on their apparent nucleic acid content (differences in fluorescence intensity) and side scatter signal (SSC): high nucleic acid (HNA) and low nucleic acid (LNA) bacteria. The function and ecological importance of these two groups is far 
61 from being fully understood (Bouvier et al. 2007; Van Wambeke et al. 2011), and several studies have

62 addressed these nucleic acid content differences in terms of ecological traits, such as bacterial activity and production (Morán et al. 2007; Ortega-Retuerta et al. 2008; Van Wambeke et al. 2011).

Two main groups of autotrophic prokaryotes dominate picoplankton: Prochlorococcus and Synechococcus. Prochlorococcus is ubiquitous in the euphotic zone of tropical oceans, being considered the most abundant photosynthetic organisms on the planet (Partensky et al. 1999b), and its discovery was only made possible with the development of flow cytometry (Chisholm et al. 1988). Prochlorococcus is discriminated by its small scattering and low red fluorescence (chlorophyll). Synechococcus is widely distributed in marine environments, being particularly abundant in well-lit and nutrient rich top layers of the oceans (Partensky et al. 1999a). One of the key parameters that allows Synechococcus populations to be discriminated by FCM is the phycoerythrin content (orange fluorescence). Different Synechococcus clades can show distinct fluorescence signatures (Olson et al. 1990; Thompson and van den Engh 2016), as a result of different phycobilisome composition (Scanlan et al. 2009). Pico- and nanoeukaryotes are important contributors to global primary productivity (Li 1994), and due to their larger cell size, they often contribute to an important share of autotrophic biomass in the oceans (Zubkov et al. 1998). Picoeukaryotes, which cells range from $0.8 \mu \mathrm{m}$ to $2-3 \mu \mathrm{m}$ (Simon et al. 1994), present well-defined cytometric signatures by FCM, while nano-eukaryotes populations are less well defined.

FCM analysis has led to numerous advances in marine microbial ecology, although cost and maintenance expenses were prohibitive for many laboratories until recently (Gasol and del Giorgio 2000; Vives-Rego et al. 2000). Since the first cytometry-based field study made by Olson, Vaulot \& Chisholm (1985), on-board flow cytometry has become a crucial tool in the investigation of both autotrophic and heterotrophic picoplanktonic communities (Legendre et al. 2001). The manufacturing of low cost compact benchtop flow cytometers such as the BD Accuri ${ }^{\mathrm{TM}} \mathrm{C} 6$, the Millipore Guava ${ }^{\circledR}$ or the Applied Biosystems Attune ${ }^{\circledR}$ has facilitated the use of FCM to study of phytoplankton communities 
around the world, due to easy handling, automatic sampling and easy transportation (a critical quality for field measurements). However, these low cost instruments can be less sensitive than laboratory based flow cytometers, due to less sophisticated optical and/or electronic systems.

A lower sensitivity is usually not a problem for bacteria which are detected after staining with strongly fluorescing dyes such as SYBR Green, or for small eukaryotes whose pigment content is relatively high. However, this is not the case for cyanobacteria like Prochlorococcus, for which the concentration of photosynthetic pigments per cell is as much as 50-100 fold lower in cells exposed to high light as a result of photo-acclimation (Sosik et al. 1989; Olson et al. 1990), creating 'dim' populations in the surface layers. Such low fluorescence explains why Prochlorococcus escaped detection by researchers using epifluorescence microscopy or even during the first use of FCM on board oceanographic ships (Olson et al. 1985). To overcome the problem of low sensitivity flow cytometers, both direct and indirect approaches to infer Prochlorococcus abundance have been developed, such as changes in cytometer optical set up to improve excitation energy or fluorescence detection (Dusenberry and Frankel 1994; Partensky et al. 1999b) and the use of mathematical corrections (Zubkov et al. 1998; Crosbie and Furnas 2001).

In this paper, we compare data obtained on marine microbial communities with two flow cytometers, the FACSCanto ${ }^{\mathrm{TM}}$ and the Accuri ${ }^{\mathrm{TM}} \mathrm{C} 6$ (hereafter named as CANTO and C6). Although manufactured by the same company (BD Biosciences, San Jose, CA, USA), these cytometers present distinct fluorescence excitation/detection technical features (Table 1). Differences in laser, optics and electronic systems can potentially affect sensitivity and resolution, influencing the accuracy of field measurements. We analyzed heterotrophic marine bacteria, photosynthetic eukaryotes and cyanobacteria on a set of marine samples from the South Atlantic Ocean (displaying both nutrient and light gradients within the water column). While both instruments produced equivalent data for bacteria and eukaryotes, cyanobacteria, especially Prochlorococcus, were severely under-estimated with the C6 instrument, and procedures previously suggested to correct the data proved ineffective. 
111 Materials and methods

112 Sampling

113 Water samples were collected onboard the R/V "Alpha Crucis", between 31/10/2013 and

$11423 / 11 / 2013$. The surveyed area was located between latitude $23^{\circ} 11^{\prime} \mathrm{S}-30^{\circ} 52^{\prime} \mathrm{S}$ and longitude $39^{\circ} 22^{\prime \prime} \mathrm{W}$

$115-49^{\circ} 09^{\prime \prime} \mathrm{W}$, along 3 transects (TR1, TR2 and TR3), in the South West Atlantic off Brazil, reaching the

1163510 meters isobath (Fig. 1). The sampling strategy comprised cross-shelf transects with 5 depths per

117 station within the euphotic zone for TR1 and TR2, as well as 12 surface samplings for TR3, for a total

118 of 102 samples. Three water masses were sampled during the cruise: the warm and oligotrophic

119 Tropical Water, the cold and nutrient rich South Atlantic Central Water and the Coastal Water, with

120 highly variable features (Castro et al. 2006). Except for TR3 samples, which were collected using a

121 polycarbonate bucket, seawater samples were collected with 12 L Niskin bottles attached to a Seabird ${ }^{\circledR}$

122 CTD-rosette system (Sea-Bird Electronics, Bellevue, WA, USA), divided into cryotubes, preserved

123 with $0.1 \%$ glutaraldehyde, final concentration (modified from Vaulot et al., 1989), incubated for 10

124 minutes in the dark, flash-frozen in liquid nitrogen and stored at $-80^{\circ} \mathrm{C}$ until analysis.

125 Flow cytometry analysis

126 Two flow cytometers were used in this study: a BD FACSCanto II $^{\mathrm{TM}}$ and a BD Accuri ${ }^{\mathrm{TM}}$ C6

127 (Table 1). Samples were counted simultaneously on both cytometers located in the same room, in order

128 to avoid any possible bias by manipulation or time span between measurements. The tubing of the C6

129 was new and fluidics were calibrated for precise volume measurements as recommended by the 130 manufacturer (Section 4.13 of manual).

131 Samples were first analyzed unstained to enumerate phototrophs. Fluorescent beads (0.95 G

132 Fluoresbrite ${ }^{\circledR}$ Polysciences, Warrington, PA) were added in each sample in order to normalize

133 parameters (Marie et al. 1997). A second analysis was performed to enumerate heterotrophic bacteria 
134 after staining with SYBR Green ${ }^{\circledR}$ (1:10000, final concentration) (Ref-S7585, Life Technologies, 135 Eugene, Oregon).

On the C6, for enumerating phytoplankton, $200 \mu \mathrm{L}$ of sample were analyzed at the "high" rate

$\left(66 \mu \mathrm{L} \cdot \mathrm{min}^{-1}\right)$ with a threshold set at 700 on red fluorescence (FL3-H). To enumerate heterotrophs, 60 $\mu \mathrm{L}$ of SYBR Green stained samples were run at "medium" rate $\left(35 \mu \mathrm{L} \cdot \mathrm{min}^{-1}\right)$ and the threshold was set at 700 on green fluorescence (FL1-H). In both cases, thresholds were determined by running $0.2 \mu \mathrm{m}$ filtered sea water sample and lowering the values until electrical or optical noise appears.

On the CANTO for enumerating phytoplankton, samples were run for 3 min with a rate of 72 $\mu \mathrm{L} . \mathrm{min}^{-1}$ and with the discriminator set on red fluorescence at 200 . For bacterial enumeration, SYBR

Green stained samples were run for $2 \mathrm{~min}$ at a rate of $60 \mu \mathrm{L} \cdot \mathrm{min}^{-1}$ and the threshold was set on green

fluorescence at 500. Flow rate was determined by the method described by Marie et al. (1997). A known volume of seawater was injected on the CANTO for at least $10 \mathrm{~min}$. Then the remaining volume is measured and the rate is determined by dividing the difference between initial and final volumes by the injection time.

Data were analyzed with the Flowing Software ${ }^{\circledR} 2.5$ (http://www.flowingsoftware.com). Each population was identified on the cytograms on the basis of its scatter and fluorescence signals (Fig. S1). Each parameter was normalized to that of the reference beads $(0.95 \mu \mathrm{m})$. Cell counts for each red fluorescence value were exported from the single parameter histogram. The resulting spreadsheet (File $\mathrm{S} 1$ ) was used in subsequent analysis with the R software (R Development Core Team, 2013).

Near the surface the red chlorophyll fluorescence of the picophytoplankton decreases due to photoacclimation (Partensky et al. 1993; Dusenberry et al. 2001; Kulk et al. 2011). Therefore, for a fraction or even all of the Prochlorococcus and Synechococcus populations, fluorescence can fall below the detection threshold (Fig. 2). For the case where only a part of the population was in the noise, we modified the correction procedure described by Crosbie and Furnas (2001) and implemented it as an $\mathrm{R}$ routine (File $\mathrm{S} 2$ ). This correction assumes that the red fluorescence distribution of these 
populations has a log-normal shape (Crosbie and Furnas 2001; Shapiro 2003) and that, when the left part of the distribution is partially in the noise, the left part can be extrapolated from the right part. The

$\mathrm{R}$ routine takes as input histograms produced by the Flowing Software ${ }^{\circledR}$ (but can be adapted to other data formats) and outputs uncorrected and corrected cell abundance data (output data examples can be found in Files S2 and S3). Three cases can occur for a given population.

1. The mode of the histogram is not visible (e.g. Fig. 2G). In this case, the population is considered to be mostly within noise, without the possibility of counting or correction. Hence, this population is removed from the dataset and labeled as 'cells in noise' by the R routine.

2. The mode is visible, but the left part of the distribution is partly below the noise level (e.g. Fig.

for deeper samples with low cell numbers resulting in noisy histograms (e.g. Fig. 2Q or 2W).

174 Therefore, the $\mathrm{R}$ routine provides a graphical output of the histogram for each sample (File S3), allowing the user to visually confirm whether the automatic labeling (case 1, 2, or 3 above) is correct.

Statistical analyses were performed with the PRISM ${ }^{\circledR} 7$ software (http://www.graphpad.com/scientificsoftware/prism).

Bacterial populations were well resolved for both CANTO and C6 for all samples (Fig. S1). High Nucleic Acid and Low Nucleic Acid bacterial populations were consistently distinguished with both cytometers and there was a very good correlation for both HNA and LNA $\left(\mathrm{R}^{2}=0.85\right.$ and 0.89 , 
statistically different from $1(p<0.0001)$ and abundances estimated by the C6 were consistently lower

184 by $10-15 \%$ compared to the CANTO. layers to the surface in response to photoacclimation. For samples near the surface, cells from both populations can be partly or totally in the noise depending on the instrument sensitivity. Fig. 2 demonstrates clearly that the C6 is less sensitive than the CANTO by at least a factor of 10 (note for example Fig. 2C and 2I for Prochlorococcus at $110 \mathrm{~m}$ for the CANTO and C6, the mode of the histogram is in the noise for the C6 and about 10 times higher than the noise level for the CANTO). With the C6, Prochlorococcus populations were completely in the noise above $100 \mathrm{~m}$ (55 out of 102 samples, Fig. 2 and 4, Table 2) and for Synechococcus partly or completely in the noise above $50 \mathrm{~m}$ (15 out of 102 samples, Fig. 2 and 4, Table 2). With the CANTO, only surface Prochlorococcus were partly in the noise and Synechococcus was always fully resolved (Fig. 2 and 4, Table 2). When cells were only partly in the noise (i.e. when the histogram mode was clearly visible, e.g. Fig. 2U), we estimated the part of the population that was in the noise using the approach proposed by Crosbie and Furnas (2001) (see Material and Methods section). The comparison between the C6 data which required correction and the CANTO data that did not require correction allowed us to assess the validity of this approach (Fig. 3C and D).

Clearly some data points that are corrected (grey squares) appear as outliers and are severely underestimated with the C6, even after correction (Fig. 3C and D). The slopes for non-corrected samples (solid circles) are significantly different from $1(p<0.0001)$, being respectively 0.75 (Prochlorococcus) and 0.77 (Synechococcus) (Fig. 3C and D), which corresponds to 25\% lower abundance on average with the C6. Vertical cross sections of two transects (Fig. 4) illustrate that, while the CANTO provides fully resolved vertical profiles for both Prochlorococcus and Synechococcus population, the data from the C6 cannot be used in the upper layer (roughly from $100 \mathrm{~m}$ to the surface). 
Pico- and Nano-eukaryotes were always above the detection limit for both instruments with excellent correlation between the two instruments $\left(\mathrm{R}^{2}=0.94\right.$ and 0.69 , respectively, Fig. 3E and F). As for the other populations, the slopes were significantly different from $1(p<0.0001)$. While picoeukaryotes were about $15 \%$ more abundant with the $\mathrm{C} 6$, it was the reverse for nanoeukaryotes 211 which were slightly underestimated by the C6.

\section{Discussion}

213 The analysis of planktonic communities by flow cytometry is complex because the distinctive 214 cell features of each population may change with depth, diel cycle and nutrient conditions (e.g. Vaulot 215 and Marie 1999). From the six planktonic groups studied here, four were well resolved by both the 216 CANTO and C6 flow cytometers: HNA and LNA heterotrophic bacteria, autotrophic pico-eukaryotes 217 and nano-eukaryotes. Abundance measured by both instruments were tightly correlated. Abundance was always slightly lower with the C6 than with the CANTO, except for picoeukaryotes. This could have resulted from an imperfect calibration of the analyzed volume for one of the instruments. While on the CANTO, the analyzed volume is manually calibrated, the C6 relies on a calibration every time tubing is changed following the manufacturer's recommendation. However, we have recently observed that the actual volume analyzed varies, even during the course of a day, and needs to be re-calibrated at fixed intervals using a procedure similar to the one used for the CANTO (D. Marie, unpublished data). The slightly lower correlation coefficient observed for nanoeukaryotes could result from the difficulty to clearly distinguish the limits of the pico and nano-eukaryote populations.

In contrast, the lower sensitivity of the C6 led a drastic underestimation or even non-detection of the cyanobacteria in the upper $100 \mathrm{~m}$ of the water column, especially for Prochlorococcus. But the phenomenon was also present for Synechococcus although it had not been recognized previously. For both populations, corrections, such as those recommended previously (Zubkov et al. 1998; Crosbie and 
231 still much lower than those obtained with the CANTO (Fig. 3C, D). The data obtained with the C6 for

232 Prochlorococcus but also Synechococcus, should be considered with great caution even when only a 233 part of the population is in the noise.

234 The oceanographic transects (Fig. 4) demonstrate that the C6 instrument would result in very 235 serious underestimates of the cyanobacteria abundance and therefore contribution to the carbon 236 biomass, at least in oligotrophic to mesotrophic waters. For Synechococcus, one solution could be to 237 trigger acquisition on PE fluorescence (FL2) which is general quite strong, but this will require to run 238 every sample twice, with the trigger on FL2 and FL3 respectively. Unfortunately this was not tested on 239 our samples. For Prochlorococcus, the only solution to overcome the problem of low sensitivity is to 240 increase either the excitation energy or the fluorescence detection through optical solutions 241 (Dusenberry and Frankel 1994; Partensky et al. 1999b).

\section{Conclusion}

The increasing affordability of benchtop flow cytometers comes with limitations in some of the equipment features, such as lower detection limits. The comparison between studies of phytoplankton communities by flow cytometry should take into account the equipment used, particularly in approaches involving populations of Prochlorococcus and Synechococcus, in which low chlorophyll concentration per cell can lead to the underestimation of their abundance in the top euphotic zone. Still these benchtop flow cytometers provide reliable data for other populations such as heterotrophic bacteria and photosynthetic eukaryotes. Our study highlight the need for careful comparison between instruments before using them for large scale oceanographic surveys, using as reference the most sensitive laboratory instruments available. 
254 Acknowledgments

255 We thank the officers and crew of the R/V Alpha Crucis for logistical support. Financial 256 support for this work was provided by the CNRS Groupement de Recherche International (GDRI) 257 "Diversity, Evolution and Biotechnology of Marine Algae", the COFECUB-CAPES project "Pico 258 Brás" (TE 871-15) and FAPESP - Fundação de Amparo à Pesquisa do Estado de São Paulo $259 \quad(2012 / 04800-9$ and 2014/15242-2). 
262

263

264

265

266

267

268

269

270

271

272

273

274

275

276

277

278

279

280

281

282

283

284

\section{References}

Bouvier, T., P. A. del Giorgio, and J. M. Gasol. 2007. A comparative study of the cytometric characteristics of High and Low nucleic-acid bacterioplankton cells from different aquatic ecosystems. Environ. Microbiol. 9: 2050-2066. doi:10.1111/j.1462-2920.2007.01321.x

Castro, B. M., F. P. Brandini, A. M. S. Pires-Vanin, and L. B. Miranda. 2006. Physical oceanography of the western Atlantic continental shelf located between $4 \mathrm{~N}$ and $34 \mathrm{~S}$, p. 209-251. In A.R. Robinson and K.H. Brink [eds.], The Sea, Volume 14A: The Global Coastal Ocean. Harvard University Press.

Chisholm, S. W., R. J. Olson, E. R. Zettler, R. Goericke, J. B. Waterbury, and N. A. Welschmeyer. 1988. A novel free-living prochlorophyte abundant in the oceanic euphotic zone. Nature 334: 340-343. doi:10.1038/334340a0

Crosbie, N., and M. Furnas. 2001. Abundance, distribution and flow- cytometric characterization of picophytoprokaryote populations in central $\left(17^{\circ} \mathrm{S}\right)$ and southern $\left(20^{\circ} \mathrm{S}\right.$ shelf waters of the Great Barrier Reef. J. Plankton Res. 23: 809-828. doi:809-828. doi:10.1093/plankt/23.8.809

Dusenberry, J. A., and S. L. Frankel. 1994. Increasing the sensitivity of a FACScan flow cytometer to study oceanic picoplankton. Limnol. Oceanogr. 39: 206-209. doi:10.4319/1o.1994.39.1.0206

Dusenberry, J. A., R. J. Olson, and S. W. Chisholm. 2001. Photoacclimation kinetics of single-cell fluorescence in laboratory and field populations of Prochlorococcus. Deep. Res. Part I Oceanogr. Res. Pap. 48: 1443-1458. doi:10.1016/S0967-0637(00)00096-0

Gasol, J. M., and P. a del Giorgio. 2000. Using flow cytometry for counting natural planktonic bacteria and understanding the structure of planktonic bacterial communities. Sci. Mar. 64: 197-224. doi:10.3989/scimar.2000.64n2197

Kulk, G., W. H. van de Poll, R. J. W. Visser, and A. G. J. Buma. 2011. Distinct differences in 
photoacclimation potential between prokaryotic and eukaryotic oceanic phytoplankton. J. Exp. Mar. Bio. Ecol. 398: 63-72. doi:10.1016/j.jembe.2010.12.011

287

Legendre, L., C. Courties, and M. Troussellier. 2001. Flow cytometry in oceanography 1989-1999: Environmental challenges and research trends. Cytometry 44: 164-172. doi:10.1002/10970320(20010701)44:3<164::AID-CYTO1108>3.0.CO;2-6

Li, W. K. W. 1994. Primary production of prochlorophytes, cyanobacteria, and eucaryotic ultraphytoplankton: Measurements from flow cytometric sorting. Limnol. Oceanogr. 39: 169-175. doi:10.4319/lo.1994.39.1.0169

Marie, D., F. Partensky, S. Jacquet, and D. Vaulot. 1997. Enumeration and cell cycle analysis of natural populations of marine picoplankton by flow cytometry using the nucleic acid stain SYBR Green I. Appl. Environ. Microbiol. 63: 186-193.

Marie, D., N. Simon, and D. Vaulot. 2005. Phytoplankton Cell Counting by Flow Cytometry, p. 253556. In R.A. Andersen [ed.], Algal culturing techniques. Academic Press.

Morán, X., A. Bode, L. Suárez, and E. Nogueira. 2007. Assessing the relevance of nucleic acid content as an indicator of marine bacterial activity. Aquat. Microb. Ecol. 46: 141-152. doi:10.3354/ame046141

Olson, R. J., S. W. Chisholm, and E. R. Zettler. 1990. Pigments, size, and distribution of Synechococcus in the North Atlantic and Pacific Oceans. Limnol. Oceanogr. 35: 45-58.

Olson, R. J., D. Vaulot, and S. W. Chisholm. 1985. Marine phytoplankton distributions measured using shipboard flow cytometry. Deep Sea Res. Part A. Oceanogr. Res. Pap. 32: 1273-1280. doi:10.1016/0198-0149(85)90009-3

Ortega-Retuerta, E., I. Reche, E. Pulido-Villena, S. Agustí, and C. Duarte. 2008. Exploring the relationship between active bacterioplankton and phytoplankton in the Southern Ocean. Aquat. Microb. Ecol. 52: 99-106. doi:10.3354/ame01216

Partensky, F., J. Blanchot, and D. Vaulot. 1999a. Differential distribution and ecology of 
Prochlorococcus and Synechococcus in oceanic waters: a review. Bull. 1'Institut

$311 \quad$ océanographique.

312 Partensky, F., W. R. Hess, and D. Vaulot. 1999b. Prochlorococcus, a marine photosynthetic prokaryote 313 of global significance. Microbiol. Mol. Biol. Rev. 63: 106-127.

314 Partensky, F., N. Hoepffner, K. W, O. Ulloa, and D. Vaulot. 1993. Photoacclimation of 315 Prochlorococcus sp. (Prochlorophyta) Strains isolated from the northern Atlantic and the 316 Mediterranean sea. Plant Physiol. 101: 285-296.

317 Scanlan, D. J., M. Ostrowski, S. Mazard, and others. 2009. Ecological genomics of marine 318 picocyanobacteria. Microbiol. Mol. Biol. Rev. 73: 249-299. doi:10.1128/MMBR.00035-08

319 Shapiro, H. M. 2003. Practical flow cytometry, 3rd Edition, by Howard M. Shapiro, M.D., Wiley-Liss, $320 \quad$ Inc., New York, 1995, 542 pages, 4th Ed.

321 Simon, N., R. G. Barlow, D. Marie, F. Partensky, D. Vaulot, and Qd. 1994. Characterization of oceanic photosynthetic picoeukaryotes by flow-cytometry. J. Phycol. 30: 922-935. doi:10.1111/j.00223646.1994.00922.x

Sosik, H. M., S. W. Chisholm, and R. J. Olson. 1989. Chlorophyll fluorescence from single cells: Interpretation of flow cytometric signals. Limnol. Oceanogr. 34: 1749-1761. doi:10.4319/1o.1989.34.8.1749

Team R Development Core. 2013. R: A language and environment for statistical computing. R Found. Stat. Comput. 1-3464.

Thompson, A. W., and G. van den Engh. 2016. A multi-laser flow cytometry method to measure single cell and population-level relative fluorescence action spectra for the targeted study and isolation of phytoplankton in complex assemblages. Limnol. Oceanogr. Methods 14: 39-49. doi:10.1002/lom3.10068 
16

335 Vaulot, D., C. Courties, and F. Partensky. 1989. A simple method to preserve oceanic phytoplankton

336 for flow cytometric analyses. Cytometry 10: 629-635. doi:10.1002/cyto.990100519

337 Vaulot, D., and D. Marie. 1999. Diel variability of photosynthetic picoplankton in the equatorial

$338 \quad$ Pacific. J. Geophys. Res. Ocean. 104: 3297-3310. doi:10.1029/98JC01333

339 Vives-Rego, J., P. Lebaron, and G. Nebe-von Caron. 2000. Current and future applications of flow 340 cytometry in aquatic microbiology. FEMS Microbiol. Rev. 24: 429-448. doi:10.1111/j.1574$341 \quad$ 6976.2000.tb00549.x

342 Van Wambeke, F., P. Catala, M. Pujo-Pay, and P. Lebaron. 2011. Vertical and longitudinal gradients in 343 HNA-LNA cell abundances and cytometric characteristics in the Mediterranean Sea. $344 \quad$ Biogeosciences 8: 1853-1863. doi:10.5194/bg-8-1853-2011

345 Zubkov, M. V, M. A. Sleigh, G. A. Tarran, P. H. Burkill, and R. J. . Leakey. 1998. Picoplanktonic 346 community structure on an Atlantic transect from $50^{\circ} \mathrm{N}$ to $50^{\circ} \mathrm{S}$. Deep Sea Res. Part I Oceanogr. 347 Res. Pap. 45: 1339-1355. doi:10.1016/S0967-0637(98)00015-6 
351 Tables

352 Table 1. Technical features of BD FACSCanto ${ }^{\mathrm{TM}}$ and BD Accuri ${ }^{\mathrm{TM}}$ C6 flow cytometers according to 353 the manufacturer.

\begin{tabular}{|c|c|c|}
\hline Features & BD FACSCanto $^{\mathrm{TM}}$ & BD Accuri'TM C6 \\
\hline Weight & $149.7 \mathrm{~kg}$ & $13.6 \mathrm{~kg}$ \\
\hline Acquisition Software & BD FACSDiva & BD CSampler ${ }^{\mathrm{TM}}$ \\
\hline Signal Processing & Digital & Digital \\
\hline Number of lasers & 2 & 2 \\
\hline Total $\mathbf{P M T}^{(\mathbf{a})}$ for fluorescence & 8 & 4 \\
\hline Laser configuration & Blue/red & Blue/red \\
\hline \multirow[t]{2}{*}{ Laser wavelength } & $488 \mathrm{~nm}, 20 \mathrm{~mW}$ solid state & $488 \mathrm{~nm} ; 50 \mathrm{~mW}$ solid state \\
\hline & $633 \mathrm{~nm}, 17 \mathrm{~mW} \mathrm{HeNe}$ & $640 \mathrm{~nm} ; 30 \mathrm{~mW}$ diode \\
\hline Excitation light & Optic fiber & Direct \\
\hline \multirow[t]{2}{*}{ Florescence sensitivity } & FITC $^{(\mathrm{b})}<100 \mathrm{MESF}^{(\mathrm{c})}$ & FITC $<150 \mathrm{MESF}$ \\
\hline & $\mathrm{PE}^{(\mathrm{d})}<50 \mathrm{MESF}$ & $\mathrm{PE}<100 \mathrm{MESF}$ \\
\hline Optical alignment & Fixed alignment & Fixed alignment \\
\hline Fluidics & Positive-pressure pump & Peristaltic pump \\
\hline Sample acquisition & 18 bits / 5 decades & 24 bits / 7 decades \\
\hline Sample processing & Tubes & Tubes/96-well plates \\
\hline
\end{tabular}

354 a) PMT: photomultiplier; b) FITC: fluorescein isothiocyanate; c) MESF: molecules of equivalent 355 soluble fluorochrome; d) PE: phycoerythrin. 
358 Table 2. Number of samples assigned as 'correction', 'no correction' and 'cells in noise' for each pico359 cyanobacteria group and equipment tested.

\begin{tabular}{llll}
\hline & No correction & Correction & Cells in noise \\
\hline CANTO - Prochlorococcus & 74 & 27 & 1 \\
C6 - Prochlorococcus & 27 & 20 & 55 \\
CANTO - Synechococcus & 101 & 1 & 0 \\
C6 - Synechococcus & 58 & 29 & 15 \\
\hline
\end{tabular}

360

361 
Figure legends

364

365

366

367

368

369

370

371

372

373

374

375

376

377

378

379

380

381

382

383

384

385

386

387

388

389

Fig. 1. Stations sampled in the South Atlantic Ocean off Brazil during the CARBOM cruise in 2013. Profiles: transect 1 (TR1, shaded circles) ; transect 2 (TR2, shaded triangles) and surface sampling, transect 3 (TR3, shaded squares). The grey scale on the right indicates bottom depths.

Figure 2. Examples of depth profiles (St. 100 and St. 114) of normalized red fluorescence distribution (relative cell number versus chlorophyll fluorescence) and cell abundance for Prochlorococcus (a-l) and Synechococcus $(\mathbf{m}-\mathbf{x})$ on BD FACSCanto ${ }^{\mathrm{TM}}$ and BD Accuri ${ }^{\mathrm{TM}}$ C6. For each distribution, it is indicated whether the cells were in the noise (Noise) or whether a correction was needed (Corr.). In the depth profiles (f, $\mathbf{l}, \mathbf{r}, \mathbf{x}$ ), solid symbols represent samples for which no correction was needed; grey symbols indicate samples for which we applied a correction (see Materials and Methods); samples within noise were removed.

Figure 3. Relationship between abundance measurements performed with BD Accuri ${ }^{\mathrm{TM}}$ C6 and BD FACSCanto $^{\mathrm{TM}}$ (in cells. $\mathrm{mL}^{-1}$ ): (a) HNA bacteria; (b) LNA bacteria; (c) Prochlorococcus; (d) Synechococcus; (e) picoeukaryotes and (f) nanoeukaryotes. For Prochlorococcus and Synechococcus: 'no correction': solid circles, 'correction': grey squares; 'cells in noise': open triangles. The coefficient of determination and the equation are indicated on each graphic. The regression line calculated from 'no correction' samples is marked in black. All the slopes differed significantly from $1(p<0.0001)$, except for LNA bacteria $(p=0.049)$.

Figure 4. Vertical abundance distribution (cells. $\mathrm{mL}^{-1}$ ) for measurements with BD FACSCanto ${ }^{\mathrm{TM}}$ (left column) and BD Accuri ${ }^{\mathrm{TM}}$ C6 (right column): Prochlorococcus (a, b, e, f) and Synechococcus (c, d, g, h). Top labels correspond to station number. Sampled points are marked as: 'no correction' (solid circles), 'correction' (grey squares), or 'cells in noise' (open triangles). Figures were drawn with the Ocean Data View software (https://odv.awi.de/). 
391 Supplementary material is available at https://figshare.com/s/a9499d9ab4f4740eb576 .

\section{Supplementary figure legend}

393 Figure S1. Cytograms of phycoerythrin versus chlorophyll fluorescence (a, b), side scatter versus 394 chlorophyll fluorescence (c, d) and side scatter versus DNA fluorescence (e, f) for sample 137 (St. 100 , 395110 meters depth) for BD FACSCanto ${ }^{\mathrm{TM}}$ and BD Accuri ${ }^{\mathrm{TM}}$ C6 analyses, showing the gating windows: 396 Prochlorococcus (pink), Synechococcus (green), picoeukaryotes (blue) nanoeukaryotes (orange), HNA 397 bacteria (yellow) and LNA bacteria (red). Calibrations beads are marked in black. 
400 Supplementary material

401 File S1. Example of input file for R routine.

\begin{tabular}{|c|c|c|c|c|c|}
\hline channel & $\begin{array}{l}\text { sample135_C6_PRO } \\
5 \mathrm{~m}\end{array}$ & $\begin{array}{l}\text { sample136_C6_PRO_ } \\
50 \mathrm{~m}\end{array}$ & $\begin{array}{l}\text { sample137_C6_PRO_ } \\
110 \mathrm{~m}\end{array}$ & $\begin{array}{l}\text { sample138_C6_PRO_ } \\
130 \mathrm{~m}\end{array}$ & \begin{tabular}{|l} 
sample139_C6_PRO \\
$170 \mathrm{~m}$
\end{tabular} \\
\hline 1 & 0 & 0 & 0 & 0 & 0 \\
\hline 2 & 0 & 0 & 0 & 0 & 0 \\
\hline 3 & 0 & 0 & 0 & 0 & 0 \\
\hline 4 & 0 & 0 & 0 & 0 & 0 \\
\hline 5 & 0 & 0 & 0 & 0 & 0 \\
\hline 6 & 0 & 0 & 0 & 0 & 0 \\
\hline 7 & 0 & 0 & 0 & 0 & 0 \\
\hline 8 & 0 & 0 & 0 & 0 & 0 \\
\hline 9 & 0 & 0 & 0 & 0 & 0 \\
\hline 10 & 0 & 0 & 0 & 0 & 0 \\
\hline 11 & 0 & 0 & 0 & 0 & 0 \\
\hline 12 & 0 & 0 & 0 & 0 & 0 \\
\hline 13 & 0 & 0 & 0 & 0 & 0 \\
\hline 14 & 0 & 0 & 0 & 0 & 0 \\
\hline 15 & 0 & 0 & 0 & 0 & 0 \\
\hline 16 & 0 & 0 & 0 & 0 & 0 \\
\hline 17 & 0 & 0 & 0 & 0 & 0 \\
\hline 18 & 0 & 0 & 0 & 0 & 0 \\
\hline 19 & 0 & 0 & 0 & 0 & 0 \\
\hline 20 & 0 & 0 & 0 & 0 & 0 \\
\hline 21 & 0 & 0 & 0 & 0 & 0 \\
\hline 22 & 0 & 0 & 0 & 0 & 0 \\
\hline 23 & 0 & 0 & 0 & 0 & 0 \\
\hline 24 & 0 & 0 & 0 & 0 & 0 \\
\hline 25 & 0 & 0 & 0 & 0 & 0 \\
\hline 26 & 0 & 0 & 0 & 0 & 0 \\
\hline 27 & 0 & 0 & 0 & 0 & 0 \\
\hline 28 & 0 & 0 & 0 & 0 & 0 \\
\hline 29 & 0 & 0 & 0 & 0 & 0 \\
\hline 30 & 0 & 0 & 0 & 0 & 0 \\
\hline 31 & 0 & 0 & 0 & 0 & 0 \\
\hline 32 & 0 & 0 & 0 & 0 & 0 \\
\hline 33 & 0 & 0 & 0 & 0 & 0 \\
\hline 34 & 0 & 0 & 0 & 0 & 0 \\
\hline 35 & 0 & 0 & 0 & 0 & 0 \\
\hline
\end{tabular}




\begin{tabular}{|c|c|c|c|c|c|}
\hline 36 & 0 & 0 & 0 & 0 & 0 \\
\hline 37 & 0 & 0 & 0 & 0 & 0 \\
\hline 38 & 0 & 0 & 0 & 0 & 0 \\
\hline 39 & 0 & 0 & 0 & 0 & 0 \\
\hline 40 & 0 & 0 & 0 & 0 & 0 \\
\hline 41 & 0 & 0 & 0 & 0 & 0 \\
\hline 42 & 0 & 0 & 0 & 0 & 0 \\
\hline 43 & 0 & 0 & 0 & 0 & 0 \\
\hline 44 & 0 & 0 & 0 & 0 & 0 \\
\hline 45 & 0 & 0 & 0 & 0 & 0 \\
\hline 46 & 0 & 0 & 0 & 0 & 0 \\
\hline 47 & 0 & 0 & 0 & 0 & 0 \\
\hline 48 & 0 & 0 & 0 & 0 & 0 \\
\hline 49 & 0 & 0 & 0 & 0 & 0 \\
\hline 50 & 0 & 0 & 0 & 0 & 0 \\
\hline 51 & 0 & 0 & 0 & 0 & 0 \\
\hline 52 & 0 & 0 & 0 & 0 & 0 \\
\hline 53 & 0 & 0 & 0 & 0 & 0 \\
\hline 54 & 0 & 0 & 0 & 0 & 0 \\
\hline 55 & 0 & 0 & 0 & 0 & 0 \\
\hline 56 & 0 & 0 & 0 & 0 & 0 \\
\hline 57 & 0 & 0 & 0 & 0 & 0 \\
\hline 58 & 0 & 0 & 0 & 0 & 0 \\
\hline 59 & 0 & 0 & 0 & 0 & 0 \\
\hline 60 & 0 & 0 & 0 & 0 & 0 \\
\hline 61 & 0 & 0 & 0 & 0 & 0 \\
\hline 62 & 0 & 0 & 0 & 0 & 0 \\
\hline 63 & 0 & 0 & 0 & 0 & 0 \\
\hline 64 & 0 & 0 & 0 & 0 & 0 \\
\hline 65 & 0 & 0 & 0 & 0 & 0 \\
\hline 66 & 0 & 0 & 0 & 0 & 0 \\
\hline 67 & 0 & 0 & 0 & 0 & 0 \\
\hline 68 & 0 & 0 & 0 & 0 & 0 \\
\hline 69 & 0 & 0 & 0 & 0 & 0 \\
\hline 70 & 0 & 0 & 0 & 0 & 0 \\
\hline 71 & 0 & 0 & 0 & 0 & 0 \\
\hline 72 & 0 & 0 & 0 & 0 & 0 \\
\hline 73 & 0 & 0 & 0 & 0 & 0 \\
\hline 74 & 0 & 0 & 0 & 0 & 0 \\
\hline 75 & 0 & 0 & 0 & 0 & 0 \\
\hline 76 & 0 & 0 & 0 & 0 & 0 \\
\hline 77 & 0 & 0 & 0 & 0 & 0 \\
\hline 78 & 0 & 0 & 0 & 0 & 0 \\
\hline
\end{tabular}




\begin{tabular}{|c|c|c|c|c|c|}
\hline 79 & 0 & 0 & 0 & 0 & 0 \\
\hline 80 & 0 & 0 & 0 & 0 & 0 \\
\hline 81 & 0 & 0 & 0 & 0 & 0 \\
\hline 82 & 0 & 0 & 0 & 0 & 0 \\
\hline 83 & 0 & 0 & 0 & 0 & 0 \\
\hline 84 & 0 & 0 & 0 & 0 & 0 \\
\hline 85 & 0 & 0 & 0 & 0 & 0 \\
\hline 86 & 0 & 0 & 0 & 0 & 0 \\
\hline 87 & 0 & 0 & 0 & 0 & 0 \\
\hline 88 & 0 & 0 & 0 & 0 & 0 \\
\hline 89 & 0 & 0 & 0 & 0 & 0 \\
\hline 90 & 0 & 0 & 0 & 0 & 0 \\
\hline 91 & 0 & 0 & 0 & 0 & 0 \\
\hline 92 & 0 & 0 & 0 & 0 & 0 \\
\hline 93 & 0 & 0 & 0 & 0 & 0 \\
\hline 94 & 0 & 0 & 0 & 0 & 0 \\
\hline 95 & 0 & 0 & 0 & 0 & 0 \\
\hline 96 & 0 & 0 & 0 & 0 & 0 \\
\hline 97 & 0 & 0 & 0 & 0 & 0 \\
\hline 98 & 0 & 0 & 0 & 0 & 0 \\
\hline 99 & 0 & 0 & 0 & 0 & 0 \\
\hline 100 & 0 & 0 & 0 & 0 & 0 \\
\hline 101 & 0 & 0 & 0 & 0 & 0 \\
\hline 102 & 0 & 0 & 0 & 0 & 0 \\
\hline 103 & 0 & 0 & 0 & 0 & 0 \\
\hline 104 & 0 & 0 & 0 & 0 & 0 \\
\hline 105 & 0 & 0 & 0 & 0 & 0 \\
\hline 106 & 0 & 0 & 0 & 0 & 0 \\
\hline \begin{tabular}{|l|}
107 \\
\end{tabular} & 0 & 0 & 0 & 0 & 0 \\
\hline 108 & 0 & 0 & 0 & 0 & 0 \\
\hline 109 & 0 & 0 & 0 & 0 & 0 \\
\hline 110 & 0 & 0 & 0 & 0 & 0 \\
\hline 111 & 0 & 0 & 0 & 0 & 0 \\
\hline 112 & 0 & 0 & 0 & 0 & 0 \\
\hline 113 & 0 & 0 & 0 & 0 & 0 \\
\hline 114 & 0 & 0 & 0 & 0 & 0 \\
\hline 115 & 0 & 0 & 0 & 0 & 0 \\
\hline 116 & 0 & 0 & 0 & 0 & 0 \\
\hline 117 & 0 & 0 & 0 & 0 & 0 \\
\hline 118 & 0 & 0 & 0 & 0 & 0 \\
\hline \begin{tabular}{|l}
119 \\
\end{tabular} & 0 & 0 & 0 & 0 & 0 \\
\hline 120 & 0 & 0 & 0 & 0 & 0 \\
\hline 121 & 0 & 0 & 0 & 0 & 0 \\
\hline
\end{tabular}




\begin{tabular}{|c|c|c|c|c|c|}
\hline 122 & 0 & 0 & 0 & 0 & 0 \\
\hline 123 & 0 & 0 & 0 & 0 & 0 \\
\hline 124 & 0 & 0 & 0 & 0 & 0 \\
\hline 125 & 0 & 0 & 0 & 0 & 0 \\
\hline 126 & 0 & 0 & 0 & 0 & 0 \\
\hline 127 & 0 & 0 & 0 & 0 & 0 \\
\hline 128 & 0 & 0 & 0 & 0 & 0 \\
\hline 129 & 0 & 0 & 0 & 0 & 0 \\
\hline 130 & 0 & 0 & 0 & 0 & 0 \\
\hline 131 & 0 & 0 & 0 & 0 & 0 \\
\hline 132 & 0 & 0 & 0 & 0 & 0 \\
\hline 133 & 0 & 0 & 0 & 0 & 0 \\
\hline 134 & 0 & 0 & 0 & 0 & 0 \\
\hline 135 & 0 & 0 & 0 & 0 & 0 \\
\hline 136 & 0 & 0 & 0 & 0 & 0 \\
\hline 137 & 0 & 0 & 0 & 0 & 0 \\
\hline 138 & 0 & 0 & 0 & 0 & 0 \\
\hline 139 & 0 & 0 & 0 & 0 & 0 \\
\hline 140 & 0 & 0 & 0 & 0 & 0 \\
\hline 141 & 0 & 0 & 0 & 0 & 0 \\
\hline 142 & 0 & 0 & 0 & 0 & 0 \\
\hline 143 & 0 & 0 & 0 & 0 & 0 \\
\hline 144 & 0 & 0 & 0 & 0 & 0 \\
\hline 145 & 0 & 0 & 0 & 0 & 0 \\
\hline 146 & 0 & 0 & 0 & 0 & 0 \\
\hline 147 & 0 & 0 & 0 & 0 & 0 \\
\hline 148 & 0 & 0 & 0 & 0 & 0 \\
\hline \begin{tabular}{|l}
149 \\
\end{tabular} & 0 & 0 & 0 & 0 & 0 \\
\hline 150 & 0 & 0 & 0 & 0 & 0 \\
\hline 151 & 0 & 0 & 0 & 0 & 0 \\
\hline 152 & 0 & 0 & 0 & 0 & 0 \\
\hline 153 & 0 & 0 & 0 & 0 & 0 \\
\hline 154 & 0 & 0 & 0 & 0 & 0 \\
\hline 155 & 0 & 0 & 0 & 0 & 0 \\
\hline 156 & 0 & 0 & 0 & 0 & 0 \\
\hline 157 & 0 & 0 & 0 & 0 & 0 \\
\hline 158 & 0 & 0 & 0 & 0 & 0 \\
\hline 159 & 0 & 0 & 0 & 0 & 0 \\
\hline 160 & 0 & 0 & 0 & 0 & 0 \\
\hline 161 & 0 & 0 & 0 & 0 & 0 \\
\hline 162 & 0 & 0 & 0 & 0 & 0 \\
\hline 163 & 0 & 0 & 0 & 0 & 0 \\
\hline 164 & 0 & 0 & 0 & 0 & 0 \\
\hline
\end{tabular}




\begin{tabular}{|c|c|c|c|c|c|}
\hline 165 & 0 & 0 & 0 & 0 & 0 \\
\hline 166 & 0 & 0 & 0 & 0 & 0 \\
\hline 167 & 0 & 0 & 0 & 0 & 0 \\
\hline 168 & 0 & 0 & 0 & 0 & 0 \\
\hline 169 & 0 & 0 & 0 & 0 & 0 \\
\hline 170 & 0 & 0 & 0 & 0 & 0 \\
\hline 171 & 0 & 0 & 0 & 0 & 0 \\
\hline 172 & 0 & 0 & 0 & 0 & 0 \\
\hline 173 & 0 & 0 & 0 & 0 & 0 \\
\hline 174 & 0 & 0 & 0 & 0 & 0 \\
\hline 175 & 0 & 0 & 0 & 0 & 0 \\
\hline 176 & 0 & 0 & 0 & 0 & 0 \\
\hline 177 & 0 & 0 & 0 & 0 & 0 \\
\hline 178 & 0 & 0 & 0 & 0 & 0 \\
\hline 179 & 0 & 0 & 0 & 0 & 0 \\
\hline 180 & 0 & 0 & 0 & 0 & 0 \\
\hline 181 & 0 & 0 & 0 & 0 & 0 \\
\hline 182 & 0 & 0 & 0 & 0 & 0 \\
\hline 183 & 0 & 0 & 0 & 0 & 0 \\
\hline 184 & 0 & 0 & 0 & 0 & 0 \\
\hline 185 & 0 & 0 & 0 & 0 & 0 \\
\hline 186 & 0 & 0 & 0 & 0 & 0 \\
\hline 187 & 0 & 0 & 0 & 0 & 0 \\
\hline 188 & 0 & 0 & 0 & 0 & 0 \\
\hline 189 & 0 & 0 & 0 & 0 & 0 \\
\hline 190 & 0 & 0 & 0 & 0 & 0 \\
\hline 191 & 0 & 0 & 0 & 0 & 0 \\
\hline 192 & 0 & 0 & 0 & 0 & 0 \\
\hline 193 & 0 & 0 & 0 & 0 & 0 \\
\hline 194 & 0 & 0 & 0 & 0 & 0 \\
\hline 195 & 0 & 0 & 0 & 0 & 0 \\
\hline 196 & 442 & 440 & 303 & 0 & 0 \\
\hline 197 & 1104 & 1055 & 963 & 0 & 0 \\
\hline 198 & 1647 & 1615 & 1519 & 9 & 0 \\
\hline 199 & 1664 & 1604 & 1696 & 203 & 0 \\
\hline 200 & 1385 & 1362 & 1440 & 545 & 0 \\
\hline 201 & 1158 & 1123 & 1241 & 851 & 0 \\
\hline 202 & 933 & 939 & 1048 & 882 & 0 \\
\hline 203 & 748 & 760 & 898 & 716 & 0 \\
\hline 204 & 590 & 591 & 745 & 543 & 0 \\
\hline 205 & 479 & 474 & 661 & 421 & 0 \\
\hline 206 & 376 & 362 & 566 & 322 & 0 \\
\hline 207 & 286 & 283 & 529 & 239 & 0 \\
\hline
\end{tabular}




\begin{tabular}{|c|c|c|c|c|c|}
\hline 208 & 203 & 198 & 494 & 184 & 0 \\
\hline 209 & 147 & 149 & 488 & 135 & 0 \\
\hline 210 & 103 & 102 & 478 & 100 & 0 \\
\hline 211 & 80 & 77 & 463 & 71 & 0 \\
\hline 212 & 56 & 56 & 475 & 53 & 0 \\
\hline 213 & 43 & 41 & 486 & 36 & 0 \\
\hline 214 & 35 & 30 & 491 & 22 & 0 \\
\hline 215 & 24 & 21 & 489 & 16 & 0 \\
\hline 216 & 16 & 12 & 492 & 13 & 1 \\
\hline 217 & 10 & 7 & 488 & 12 & 6 \\
\hline 218 & 9 & 5 & 501 & 12 & 9 \\
\hline 219 & 7 & 5 & 491 & 9 & 11 \\
\hline 220 & 6 & 6 & 509 & 7 & 10 \\
\hline 221 & 3 & 5 & 507 & 6 & 10 \\
\hline 222 & 2 & 4 & 511 & 7 & 9 \\
\hline 223 & 2 & 3 & 491 & 7 & 8 \\
\hline 224 & 3 & 3 & 472 & 5 & 8 \\
\hline 225 & 2 & 3 & 450 & 5 & 9 \\
\hline 226 & 2 & 2 & 435 & 5 & 8 \\
\hline 227 & 1 & 1 & 408 & 8 & 9 \\
\hline 228 & 0 & 0 & 384 & 9 & 8 \\
\hline 229 & 0 & 0 & 357 & 11 & 9 \\
\hline 230 & 1 & 0 & 343 & 10 & 7 \\
\hline 231 & 2 & 1 & 330 & 11 & 8 \\
\hline 232 & 2 & 1 & 302 & 11 & 8 \\
\hline 233 & 1 & 1 & 271 & 14 & 8 \\
\hline 234 & 1 & 0 & 237 & 16 & 6 \\
\hline 235 & 1 & 1 & 224 & 18 & 6 \\
\hline 236 & 1 & 0 & 205 & 17 & 6 \\
\hline 237 & 0 & 0 & 190 & 20 & 7 \\
\hline 238 & 1 & 0 & 180 & 22 & 7 \\
\hline 239 & 1 & 0 & 175 & 31 & 7 \\
\hline 240 & 1 & 0 & 166 & 34 & 7 \\
\hline 241 & 0 & 0 & 160 & 35 & 8 \\
\hline 242 & 0 & 0 & 156 & 43 & 11 \\
\hline 243 & 0 & 0 & 157 & 48 & 14 \\
\hline 244 & 0 & 0 & 149 & 58 & 16 \\
\hline 245 & 0 & 0 & 140 & 59 & 20 \\
\hline 246 & 0 & 0 & 143 & 66 & 22 \\
\hline 247 & 0 & 0 & 148 & 71 & 24 \\
\hline 248 & 0 & 0 & 148 & 84 & 25 \\
\hline 249 & 0 & 0 & 142 & 91 & 33 \\
\hline 250 & 0 & 0 & 134 & 94 & 40 \\
\hline
\end{tabular}




\begin{tabular}{|c|c|c|c|c|c|}
\hline 251 & 0 & 0 & 136 & 101 & 46 \\
\hline 252 & 0 & 0 & 131 & 112 & 48 \\
\hline 253 & 0 & 0 & 124 & 126 & 54 \\
\hline 254 & 0 & 0 & 112 & 130 & 56 \\
\hline 255 & 0 & 0 & 107 & 126 & 67 \\
\hline 256 & 0 & 0 & 107 & 127 & 68 \\
\hline 257 & 0 & 0 & 106 & 127 & 77 \\
\hline 258 & 0 & 0 & 97 & 125 & 75 \\
\hline 259 & 0 & 0 & 85 & 121 & 74 \\
\hline 260 & 0 & 0 & 68 & 114 & 75 \\
\hline 261 & 0 & 0 & 56 & 120 & 73 \\
\hline 262 & 0 & 0 & 51 & 117 & 79 \\
\hline 263 & 0 & 0 & 48 & 123 & 75 \\
\hline 264 & 0 & 0 & 46 & 108 & 73 \\
\hline 265 & 0 & 0 & 39 & 107 & 71 \\
\hline 266 & 0 & 0 & 34 & 93 & 68 \\
\hline 267 & 0 & 0 & 27 & 89 & 64 \\
\hline 268 & 0 & 0 & 19 & 75 & 61 \\
\hline 269 & 0 & 0 & 13 & 73 & 60 \\
\hline 270 & 0 & 0 & 10 & 73 & 59 \\
\hline 271 & 0 & 0 & 11 & 65 & 55 \\
\hline 272 & 0 & 0 & 10 & 56 & 48 \\
\hline 273 & 0 & 0 & 8 & 43 & 43 \\
\hline 274 & 0 & 0 & 6 & 39 & 36 \\
\hline 275 & 0 & 0 & 5 & 35 & 36 \\
\hline 276 & 0 & 0 & 3 & 27 & 32 \\
\hline 277 & 0 & 0 & 3 & 26 & 28 \\
\hline 278 & 0 & 0 & 3 & 18 & 22 \\
\hline 279 & 0 & 0 & 3 & 17 & 18 \\
\hline 280 & 0 & 0 & 3 & 13 & 20 \\
\hline 281 & 0 & 0 & 2 & 11 & 18 \\
\hline 282 & 0 & 0 & 3 & 9 & 18 \\
\hline 283 & 0 & 0 & 3 & 6 & 13 \\
\hline 284 & 0 & 0 & 4 & 5 & 10 \\
\hline 285 & 0 & 0 & 3 & 5 & 7 \\
\hline 286 & 0 & 0 & 2 & 5 & 9 \\
\hline 287 & 0 & 0 & 2 & 5 & 10 \\
\hline 288 & 0 & 0 & 1 & 3 & 12 \\
\hline 289 & 0 & 0 & 2 & 2 & 8 \\
\hline 290 & 0 & 0 & 1 & 2 & 6 \\
\hline 291 & 0 & 0 & 1 & 3 & 4 \\
\hline 292 & 0 & 0 & 1 & 3 & 4 \\
\hline 293 & 0 & 0 & 0 & 2 & 3 \\
\hline
\end{tabular}




\begin{tabular}{|c|c|c|c|c|c|}
\hline 294 & 0 & 0 & 0 & 1 & 2 \\
\hline 295 & 0 & 0 & 0 & 1 & 1 \\
\hline 296 & 0 & 0 & 0 & 1 & 2 \\
\hline 297 & 0 & 0 & 0 & 1 & 2 \\
\hline 298 & 0 & 0 & 0 & 0 & 1 \\
\hline 299 & 0 & 0 & 0 & 0 & 2 \\
\hline 300 & 0 & 0 & 0 & 0 & 3 \\
\hline 301 & 0 & 0 & 0 & 0 & 3 \\
\hline 302 & 0 & 0 & 0 & 0 & 2 \\
\hline 303 & 0 & 0 & 0 & 0 & 1 \\
\hline 304 & 0 & 0 & 0 & 0 & 1 \\
\hline 305 & 0 & 0 & 0 & 0 & 2 \\
\hline 306 & 0 & 0 & 0 & 0 & 1 \\
\hline 307 & 0 & 0 & 0 & 0 & 0 \\
\hline 308 & 0 & 0 & 0 & 0 & 0 \\
\hline 309 & 0 & 0 & 0 & 0 & 0 \\
\hline 310 & 0 & 0 & 0 & 0 & 0 \\
\hline 311 & 0 & 0 & 0 & 0 & 0 \\
\hline 312 & 0 & 0 & 0 & 0 & 0 \\
\hline 313 & 0 & 0 & 0 & 0 & 0 \\
\hline 314 & 0 & 0 & 0 & 0 & 0 \\
\hline 315 & 0 & 0 & 0 & 0 & 0 \\
\hline 316 & 0 & 0 & 0 & 0 & 0 \\
\hline 317 & 0 & 0 & 0 & 0 & 0 \\
\hline 318 & 0 & 0 & 0 & 0 & 0 \\
\hline 319 & 0 & 0 & 0 & 0 & 0 \\
\hline 320 & 0 & 0 & 0 & 0 & 0 \\
\hline 321 & 0 & 0 & 0 & 0 & 0 \\
\hline 322 & 0 & 0 & 0 & 0 & 0 \\
\hline 323 & 0 & 0 & 0 & 0 & 0 \\
\hline 324 & 0 & 0 & 0 & 0 & 0 \\
\hline 325 & 0 & 0 & 0 & 0 & 0 \\
\hline 326 & 0 & 0 & 0 & 0 & 0 \\
\hline 327 & 0 & 0 & 0 & 0 & 0 \\
\hline 328 & 0 & 0 & 0 & 0 & 0 \\
\hline 329 & 0 & 0 & 0 & 0 & 0 \\
\hline 330 & 0 & 0 & 0 & 0 & 0 \\
\hline 331 & 0 & 0 & 0 & 0 & 0 \\
\hline 332 & 0 & 0 & 0 & 0 & 0 \\
\hline 333 & 0 & 0 & 0 & 0 & 0 \\
\hline 334 & 0 & 0 & 0 & 0 & 0 \\
\hline 335 & 0 & 0 & 0 & 0 & 0 \\
\hline 336 & 0 & 0 & 0 & 0 & 0 \\
\hline
\end{tabular}




\begin{tabular}{|c|c|c|c|c|c|}
\hline 337 & 0 & 0 & 0 & 0 & 0 \\
\hline 338 & 0 & 0 & 0 & 0 & 0 \\
\hline 339 & 0 & 0 & 0 & 0 & 0 \\
\hline 340 & 0 & 0 & 0 & 0 & 0 \\
\hline 341 & 0 & 0 & 0 & 0 & 0 \\
\hline 342 & 0 & 0 & 0 & 0 & 0 \\
\hline 343 & 0 & 0 & 0 & 0 & 0 \\
\hline 344 & 0 & 0 & 0 & 0 & 0 \\
\hline 345 & 0 & 0 & 0 & 0 & 0 \\
\hline 346 & 0 & 0 & 0 & 0 & 0 \\
\hline 347 & 0 & 0 & 0 & 0 & 0 \\
\hline 348 & 0 & 0 & 0 & 0 & 0 \\
\hline 349 & 0 & 0 & 0 & 0 & 0 \\
\hline 350 & 0 & 0 & 0 & 0 & 0 \\
\hline 351 & 0 & 0 & 0 & 0 & 0 \\
\hline 352 & 0 & 0 & 0 & 0 & 0 \\
\hline 353 & 0 & 0 & 0 & 0 & 0 \\
\hline 354 & 0 & 0 & 0 & 0 & 0 \\
\hline 355 & 0 & 0 & 0 & 0 & 0 \\
\hline 356 & 0 & 0 & 0 & 0 & 0 \\
\hline 357 & 0 & 0 & 0 & 0 & 0 \\
\hline 358 & 0 & 0 & 0 & 0 & 0 \\
\hline 359 & 0 & 0 & 0 & 0 & 0 \\
\hline 360 & 0 & 0 & 0 & 0 & 0 \\
\hline 361 & 0 & 0 & 0 & 0 & 0 \\
\hline 362 & 0 & 0 & 0 & 0 & 0 \\
\hline 363 & 0 & 0 & 0 & 0 & 0 \\
\hline 364 & 0 & 0 & 0 & 0 & 0 \\
\hline 365 & 0 & 0 & 0 & 0 & 0 \\
\hline 366 & 0 & 0 & 0 & 0 & 0 \\
\hline 367 & 0 & 0 & 0 & 0 & 0 \\
\hline 368 & 0 & 0 & 0 & 0 & 0 \\
\hline 369 & 0 & 0 & 0 & 0 & 0 \\
\hline 370 & 0 & 0 & 0 & 0 & 0 \\
\hline 371 & 0 & 0 & 0 & 0 & 0 \\
\hline 372 & 0 & 0 & 0 & 0 & 0 \\
\hline 373 & 0 & 0 & 0 & 0 & 0 \\
\hline 374 & 0 & 0 & 0 & 0 & 0 \\
\hline 375 & 0 & 0 & 0 & 0 & 0 \\
\hline 376 & 0 & 0 & 0 & 0 & 0 \\
\hline 377 & 0 & 0 & 0 & 0 & 0 \\
\hline 378 & 0 & 0 & 0 & 0 & 0 \\
\hline 379 & 0 & 0 & 0 & 0 & 0 \\
\hline
\end{tabular}




\begin{tabular}{|c|c|c|c|c|c|}
\hline 380 & 0 & 0 & 0 & 0 & 0 \\
\hline 381 & 0 & 0 & 0 & 0 & 0 \\
\hline 382 & 0 & 0 & 0 & 0 & 0 \\
\hline 383 & 0 & 0 & 0 & 0 & 0 \\
\hline 384 & 0 & 0 & 0 & 0 & 0 \\
\hline 385 & 0 & 0 & 0 & 0 & 0 \\
\hline 386 & 0 & 0 & 0 & 0 & 0 \\
\hline 387 & 0 & 0 & 0 & 0 & 0 \\
\hline 388 & 0 & 0 & 0 & 0 & 0 \\
\hline 389 & 0 & 0 & 0 & 0 & 0 \\
\hline 390 & 0 & 0 & 0 & 0 & 0 \\
\hline 391 & 0 & 0 & 0 & 0 & 0 \\
\hline 392 & 0 & 0 & 0 & 0 & 0 \\
\hline 393 & 0 & 0 & 0 & 0 & 0 \\
\hline 394 & 0 & 0 & 0 & 0 & 0 \\
\hline 395 & 0 & 0 & 0 & 0 & 0 \\
\hline 396 & 0 & 0 & 0 & 0 & 0 \\
\hline 397 & 0 & 0 & 0 & 0 & 0 \\
\hline 398 & 0 & 0 & 0 & 0 & 0 \\
\hline 399 & 0 & 0 & 0 & 0 & 0 \\
\hline 400 & 0 & 0 & 0 & 0 & 0 \\
\hline 401 & 0 & 0 & 0 & 0 & 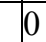 \\
\hline 402 & 0 & 0 & 0 & 0 & 0 \\
\hline 403 & 0 & 0 & 0 & 0 & 0 \\
\hline 404 & 0 & 0 & 0 & 0 & 0 \\
\hline 405 & 0 & 0 & 0 & 0 & 0 \\
\hline 406 & 0 & 0 & 0 & 0 & 0 \\
\hline 407 & 0 & 0 & 0 & 0 & 0 \\
\hline 408 & 0 & 0 & 0 & 0 & 0 \\
\hline 409 & 0 & 0 & 0 & 0 & 0 \\
\hline 410 & 0 & 0 & 0 & 0 & 0 \\
\hline 411 & 0 & 0 & 0 & 0 & 0 \\
\hline 412 & 0 & 0 & 0 & 0 & 0 \\
\hline 413 & 0 & 0 & 0 & 0 & 0 \\
\hline 414 & 0 & 0 & 0 & 0 & 0 \\
\hline 415 & 0 & 0 & 0 & 0 & 0 \\
\hline 416 & 0 & 0 & 0 & 0 & 0 \\
\hline 417 & 0 & 0 & 0 & 0 & 0 \\
\hline 418 & 0 & 0 & 0 & 0 & 0 \\
\hline 419 & 0 & 0 & 0 & 0 & 0 \\
\hline 420 & 0 & 0 & 0 & 0 & 0 \\
\hline 421 & 0 & 0 & 0 & 0 & 0 \\
\hline 422 & 0 & 0 & 0 & 0 & 0 \\
\hline
\end{tabular}




\begin{tabular}{|c|c|c|c|c|c|}
\hline 423 & 0 & 0 & 0 & 0 & 0 \\
\hline 424 & 0 & 0 & 0 & 0 & 0 \\
\hline 425 & 0 & 0 & 0 & 0 & 0 \\
\hline 426 & 0 & 0 & 0 & 0 & 0 \\
\hline 427 & 0 & 0 & 0 & 0 & 0 \\
\hline 428 & 0 & 0 & 0 & 0 & 0 \\
\hline 429 & 0 & 0 & 0 & 0 & 0 \\
\hline 430 & 0 & 0 & 0 & 0 & 0 \\
\hline 431 & 0 & 0 & 0 & 0 & 0 \\
\hline 432 & 0 & 0 & 0 & 0 & 0 \\
\hline 433 & 0 & 0 & 0 & 0 & 0 \\
\hline 434 & 0 & 0 & 0 & 0 & 0 \\
\hline 435 & 0 & 0 & 0 & 0 & 0 \\
\hline 436 & 0 & 0 & 0 & 0 & 0 \\
\hline 437 & 0 & 0 & 0 & 0 & 0 \\
\hline 438 & 0 & 0 & 0 & 0 & 0 \\
\hline 439 & 0 & 0 & 0 & 0 & 0 \\
\hline 440 & 0 & 0 & 0 & 0 & 0 \\
\hline 441 & 0 & 0 & 0 & 0 & 0 \\
\hline 442 & 0 & 0 & 0 & 0 & 0 \\
\hline 443 & 0 & 0 & 0 & 0 & 0 \\
\hline 444 & 0 & 0 & 0 & 0 & 0 \\
\hline 445 & 0 & 0 & 0 & 0 & 0 \\
\hline 446 & 0 & 0 & 0 & 0 & 0 \\
\hline 447 & 0 & 0 & 0 & 0 & 0 \\
\hline 448 & 0 & 0 & 0 & 0 & 0 \\
\hline 449 & 0 & 0 & 0 & 0 & 0 \\
\hline 450 & 0 & 0 & 0 & 0 & 0 \\
\hline 451 & 0 & 0 & 0 & 0 & 0 \\
\hline 452 & 0 & 0 & 0 & 0 & 0 \\
\hline 453 & 0 & 0 & 0 & 0 & 0 \\
\hline 454 & 0 & 0 & 0 & 0 & 0 \\
\hline 455 & 0 & 0 & 0 & 0 & 0 \\
\hline 456 & 0 & 0 & 0 & 0 & 0 \\
\hline 457 & 0 & 0 & 0 & 0 & 0 \\
\hline 458 & 0 & 0 & 0 & 0 & 0 \\
\hline 459 & 0 & 0 & 0 & 0 & 0 \\
\hline 460 & 0 & 0 & 0 & 0 & 0 \\
\hline 461 & 0 & 0 & 0 & 0 & 0 \\
\hline 462 & 0 & 0 & 0 & 0 & 0 \\
\hline 463 & 0 & 0 & 0 & 0 & 0 \\
\hline 464 & 0 & 0 & 0 & 0 & 0 \\
\hline 465 & 0 & 0 & 0 & 0 & 0 \\
\hline
\end{tabular}




\begin{tabular}{|c|c|c|c|c|c|}
\hline 466 & 0 & 0 & 0 & 0 & 0 \\
\hline 467 & 0 & 0 & 0 & 0 & 0 \\
\hline 468 & 0 & 0 & 0 & 0 & 0 \\
\hline 469 & 0 & 0 & 0 & 0 & 0 \\
\hline 470 & 0 & 0 & 0 & 0 & 0 \\
\hline 471 & 0 & 0 & 0 & 0 & 0 \\
\hline 472 & 0 & 0 & 0 & 0 & 0 \\
\hline 473 & 0 & 0 & 0 & 0 & 0 \\
\hline 474 & 0 & 0 & 0 & 0 & 0 \\
\hline 475 & 0 & 0 & 0 & 0 & 0 \\
\hline 476 & 0 & 0 & 0 & 0 & 0 \\
\hline 477 & 0 & 0 & 0 & 0 & 0 \\
\hline 478 & 0 & 0 & 0 & 0 & 0 \\
\hline 479 & 0 & 0 & 0 & 0 & 0 \\
\hline 480 & 0 & 0 & 0 & 0 & 0 \\
\hline 481 & 0 & 0 & 0 & 0 & 0 \\
\hline 482 & 0 & 0 & 0 & 0 & 0 \\
\hline 483 & 0 & 0 & 0 & 0 & 0 \\
\hline 484 & 0 & 0 & 0 & 0 & 0 \\
\hline 485 & 0 & 0 & 0 & 0 & 0 \\
\hline 486 & 0 & 0 & 0 & 0 & 0 \\
\hline 487 & 0 & 0 & 0 & 0 & 0 \\
\hline 488 & 0 & 0 & 0 & 0 & 0 \\
\hline 489 & 0 & 0 & 0 & 0 & 0 \\
\hline 490 & 0 & 0 & 0 & 0 & 0 \\
\hline 491 & 0 & 0 & 0 & 0 & 0 \\
\hline 492 & 0 & 0 & 0 & 0 & 0 \\
\hline 493 & 0 & 0 & 0 & 0 & 0 \\
\hline 494 & 0 & 0 & 0 & 0 & 0 \\
\hline 495 & 0 & 0 & 0 & 0 & 0 \\
\hline 496 & 0 & 0 & 0 & 0 & 0 \\
\hline 497 & 0 & 0 & 0 & 0 & 0 \\
\hline 498 & 0 & 0 & 0 & 0 & 0 \\
\hline 499 & 0 & 0 & 0 & 0 & 0 \\
\hline 500 & 0 & 0 & 0 & 0 & 0 \\
\hline
\end{tabular}


404 File S2. R routine to correct abundance when populations are partly in noise.

405

$R$ code

407

The code below describes how to implement an $\mathrm{R}$ routine to correct the abundance of 408 picoplanktonic populations based on their red fluorescence distribution. All libraries used here are freely available from $\mathrm{R}$ repositories. The input file used in this examples is named as Pro_C6.txt (See input file example File S1). This file has been created by exporting FL3 (chlorophyll) histogram from the Flowing Software (http://www.flowingsoftware.com) combining different samples into a single file. The first column contains the channel number and each following column corresponds to a different sample with rows corresponding to cell counts in each channel. Such a file could be created with any flow cytometry software. After running the cyto_plot function, a pdf output file is created named "Pro_C6.txt 1.0 .pdf" which contains all histograms from the input file (see File S3)and the file statistics (sample, uncorrected and corrected total cell abundance) are available as a data frame in the $\mathrm{R}$ session (see example at bottom of this file)

\# Example of use of cyto_plot function (run first the $R$ code below to define the necessary functions)

\# Example of statistics output

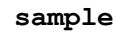

429

430 
$433 \quad R$ code

434 \# Install libraries

435 library("ggplot2")

436 library ("reshape2")

437 library("plyr")

438 library("scales")

439 require(grid)

440

\# Set the working directory where the files are located

442

setwd ("C:/My Documents/cytometry data/")

443

444 \# Define basic parameters

445 decades_Canto $=5$

446 decades_C6 $=7$

447 channel_min_Canto $=100$

448 channel_min_c6 $=214$

449 xmin_Canto $=10$

$450 \quad x m i n \_c 6=1000$

451 xmax_Canto $=10000$

452 xmax_c6 $=100000$

453 channel_max $=500$

454 point <- format_format (big.mark = "", decimal.mark = ".", scientific = TRUE)

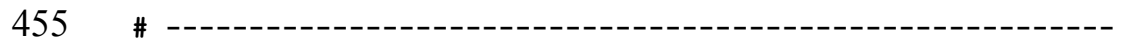

456 \# cell_correct(channel, cell_number, cell_smooth)

457 \# Arguments

458 \# channel : vector containing the channels (from 1 to 500 in the present case)

$459 \#$ cell_number : vector containing cell abundance in each channel

460 \# cell_smooth : vector containing smoothed cell abundance in each channel

461 \# Description

462 \# This function determines in which case we are ("no correction", "cells in noise" or "correction")and

463 return the corrected cell abundance in the latter case.

465 cell_correct<-function(channel, cell_number, cell_smooth)

$466\{$ df<-data.frame (channel, cell_number, cell_smooth) \# create a data frame

467 i min<-which.min(channel) \# determine the minimum channel 
i_max<-which.max (channel)

\# determine the maximum channel

i_cell_max<-which.max (cell_smooth)

\# determine in which channel is the histogram mode

470

\# "no correction" : cell abundance in the first channel is 5 times lower than abundance at the maximum

if (cell_smooth [i_cell_max] $>5 * \operatorname{cel}{ }_{\left.\text {___smooth }\left[i \_m i n\right]\right)}$

$\{$ cell_correct<-"no correction" \}

474

\# "cells in noise" : maximum of cell abundance is in the first channel

475

else $\{$ if (i_cell_max==i_min)

476

$\{$ cell_correct<-"cells in noise"

\# "correction" : all the other cases, we then apply a correction by computing the total cell abundance

as twice the number of cells in the channels right of the histogram maximum

else

\#cyto_plot(file_name, decades, channel_min, xmin, xmax)

cyto_plot<-function(file_name, decades, channel_min, xmin, xmax) 
cell_smooth=as.vector (smooth (cell_number)) )

\# normalize histogram so that maximum abundance is equal to 1

\# transform log channel to linear scale for plotting

else

fluo $=\left(10^{\wedge} 7\right)^{\wedge}($ channel/channel_max $\left.\left.)\right)\right\}$

\# save plots as pdf

$$
\text { stats }
$$


540 File S3. Example of output file for R routine.

541

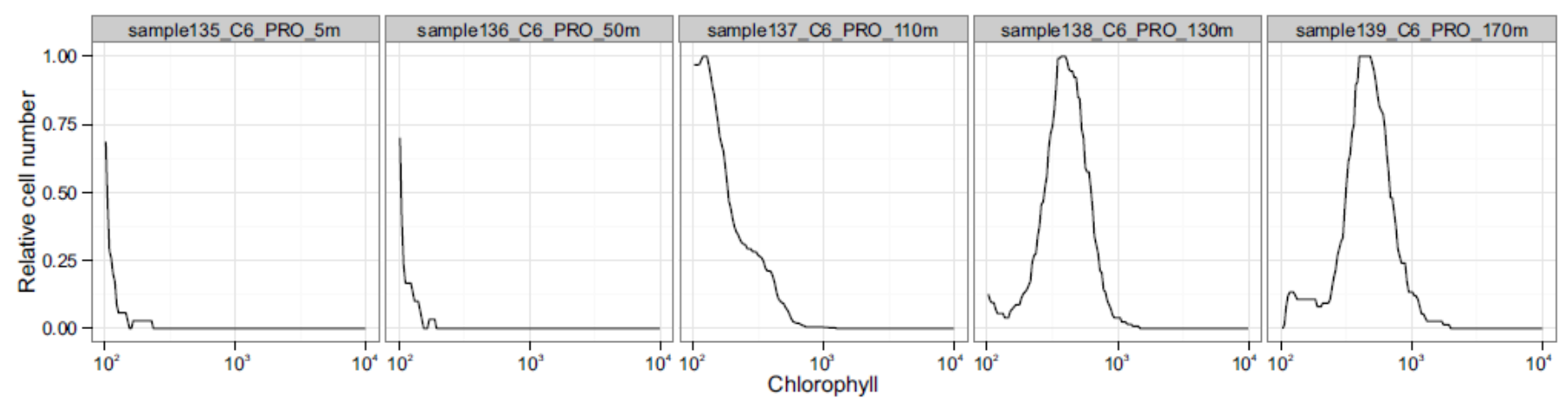




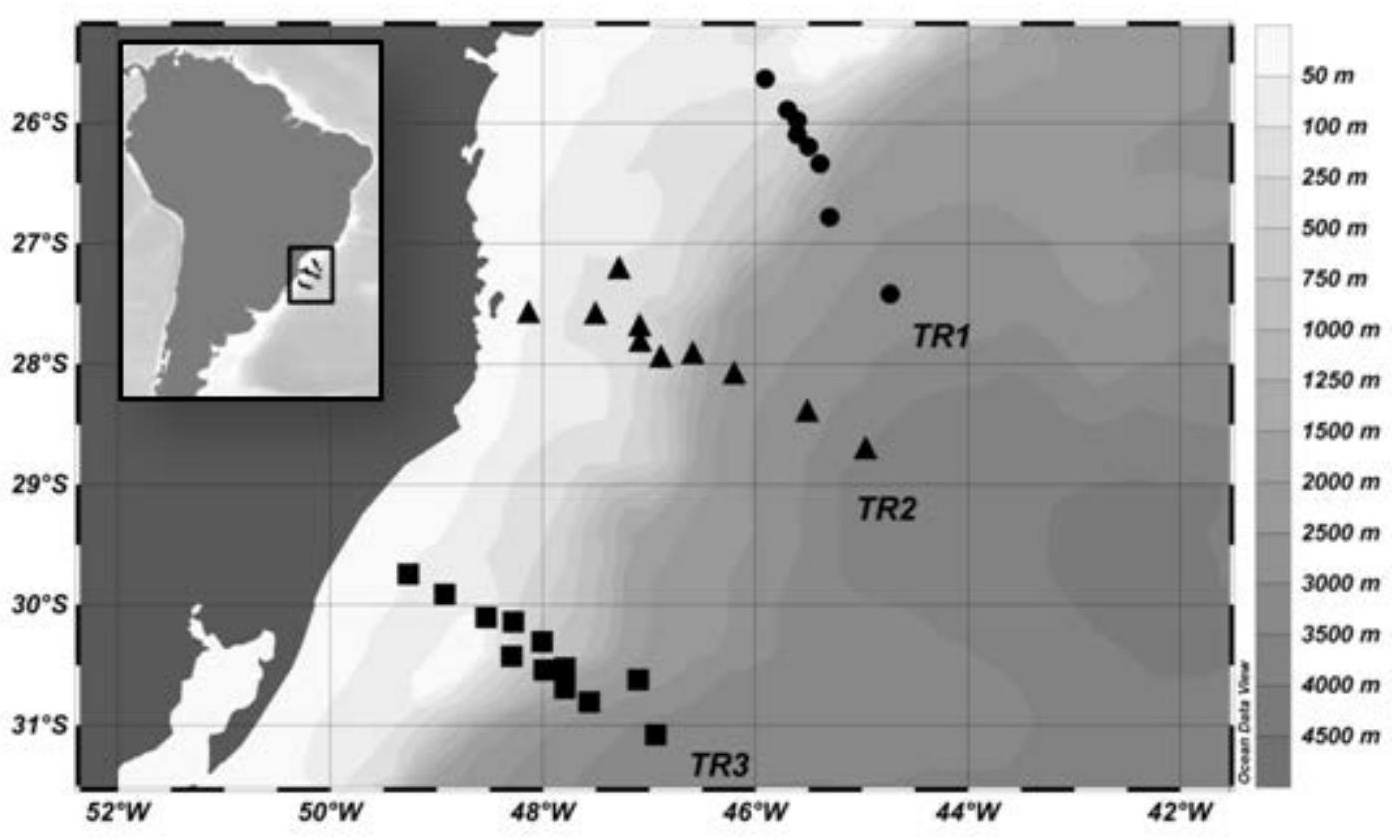



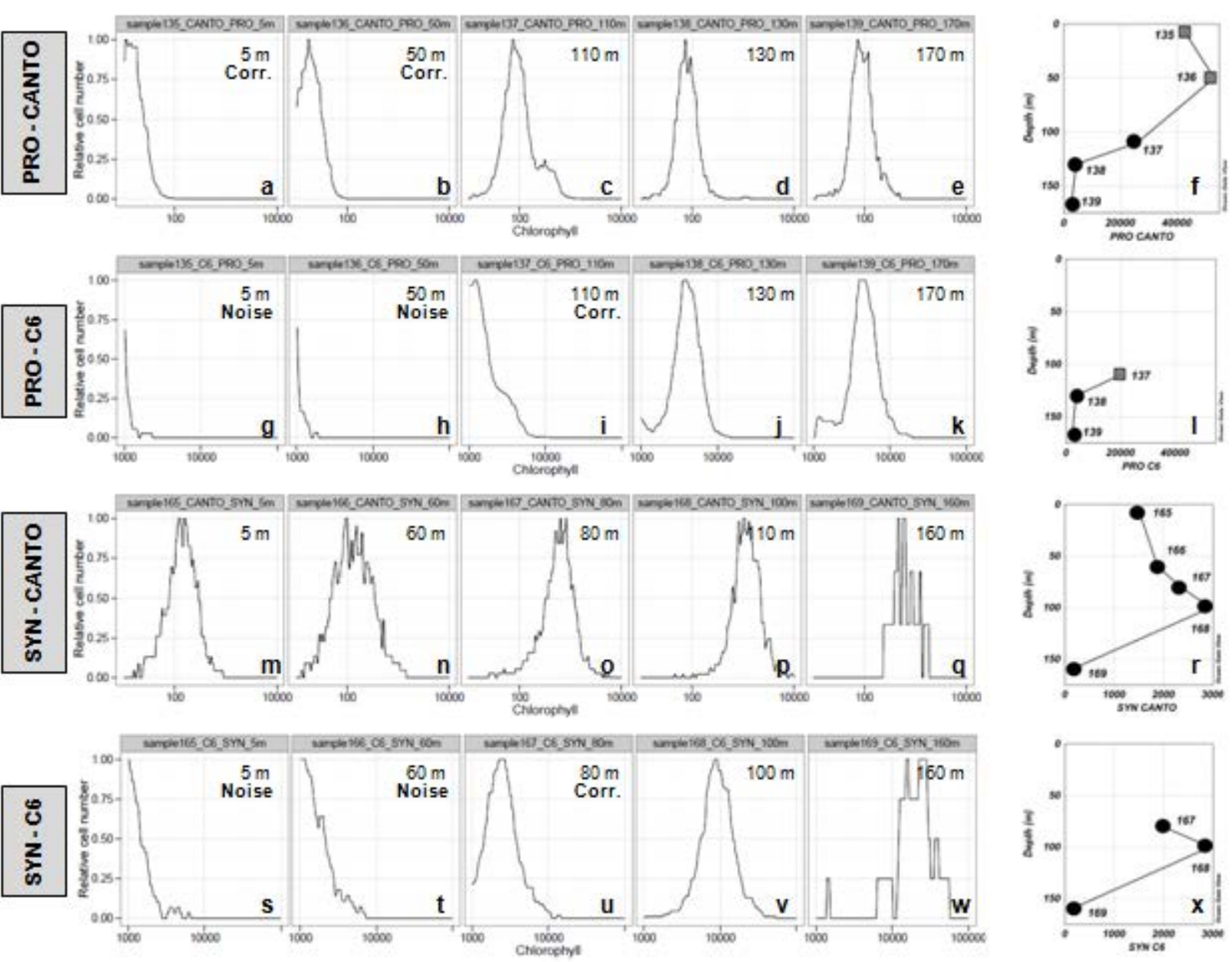
a

HNA

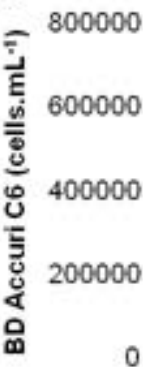

0

$400000 \quad 800000$

BD FacsCANTO (cells.mL-1)

c

(1)

e
Prochlorococcus

300000
250000
200000
150000
100000
50000
0

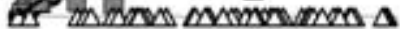

$\begin{array}{llll}0 & 100000 & 200000 & 300000\end{array}$

BD FacsCANTO (cells.mL $\mathrm{mL}^{-1}$ )

picoeukaryotes

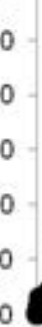

0

BD FacsCANTO (cells.mL-1) b

-no correction

$y=0.85 x+9449$.

$R^{2}=0.85$

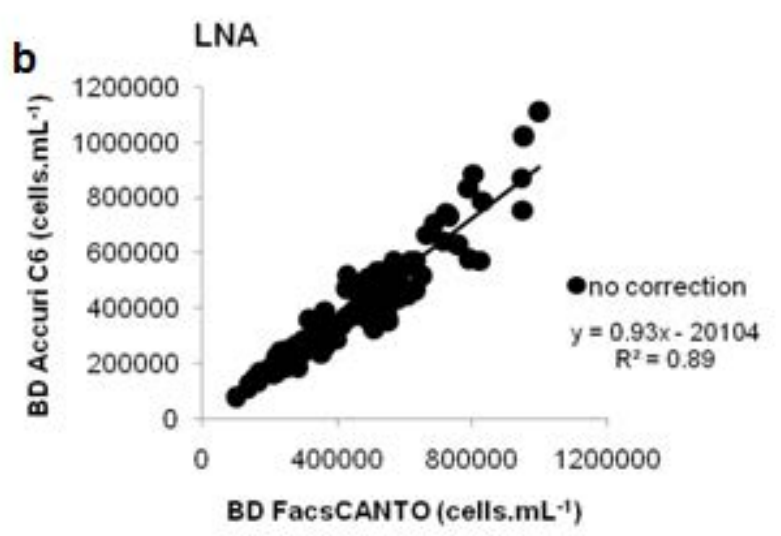

d Synechococcus

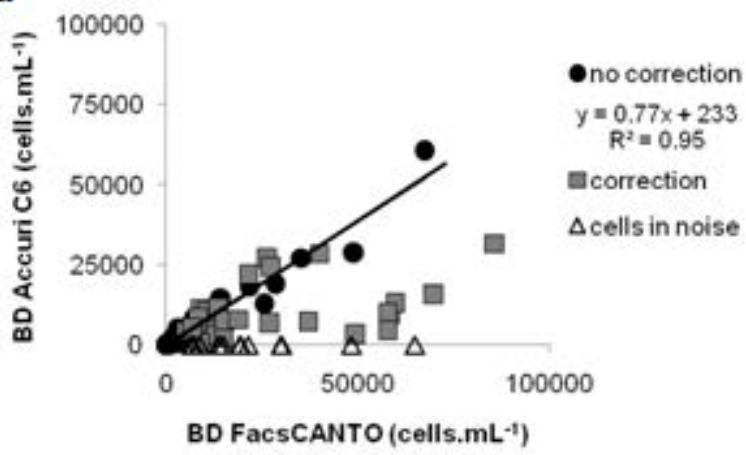

f

-no correction

$y=1.15 x+149.9$

$R^{2}=0.94$

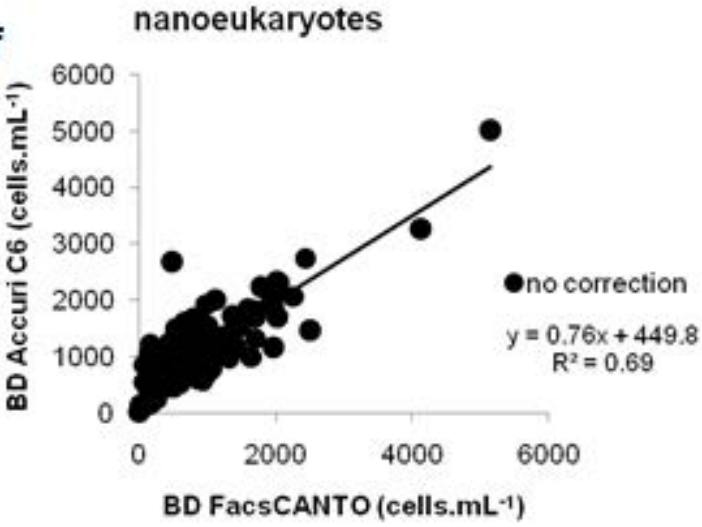




\section{a PRO CANTO}

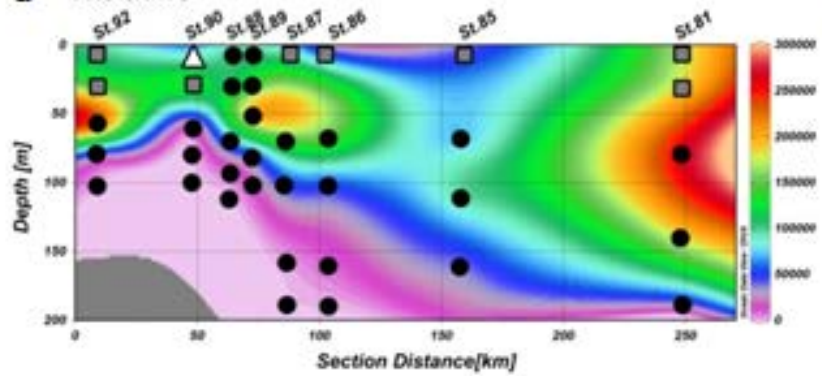

b PRO CANTO

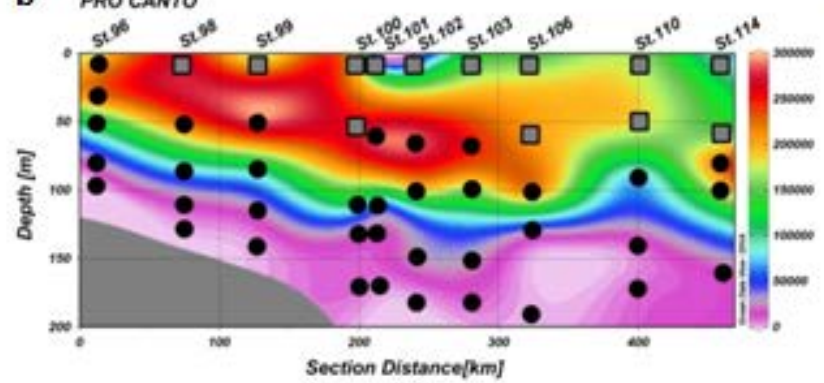

C SYNCANTO

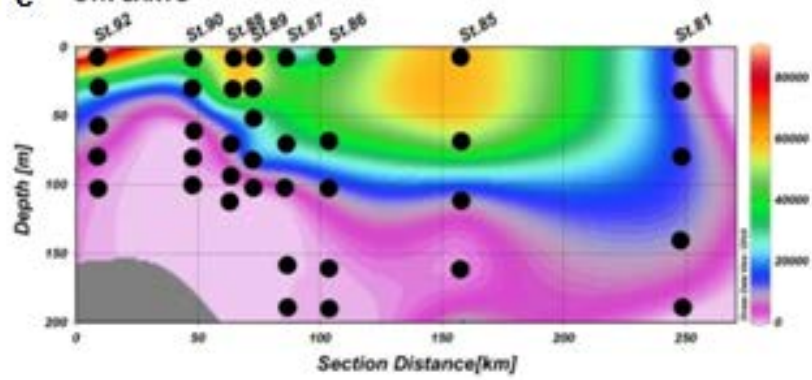

d SIN CANTO

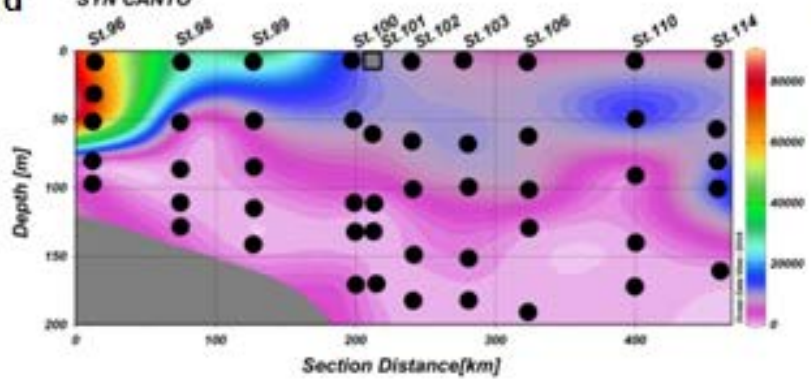

\section{e PROC6}

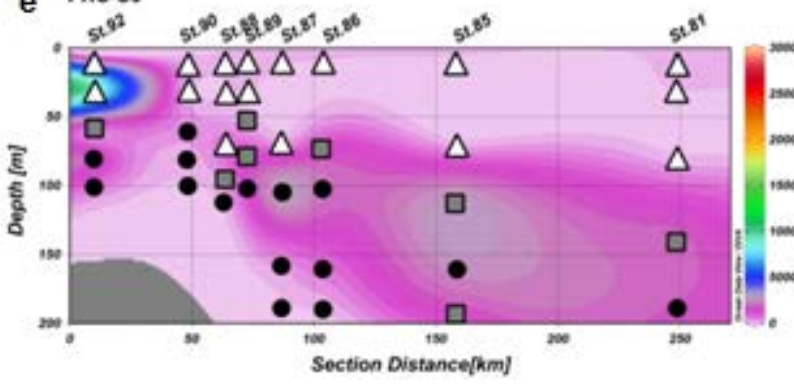

f PRO C6
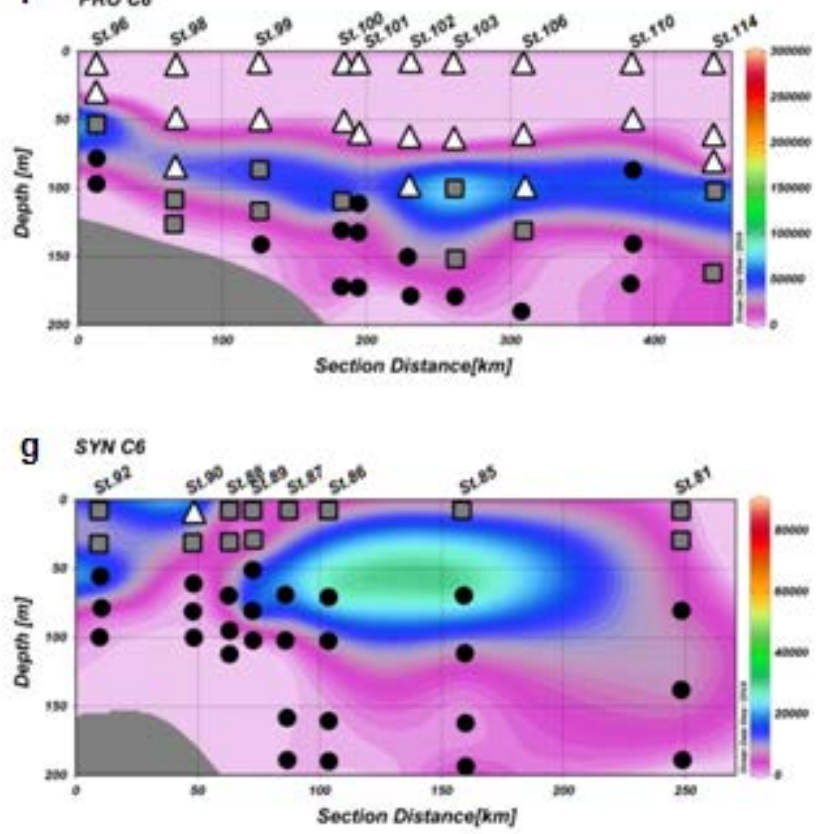

h sYNCs

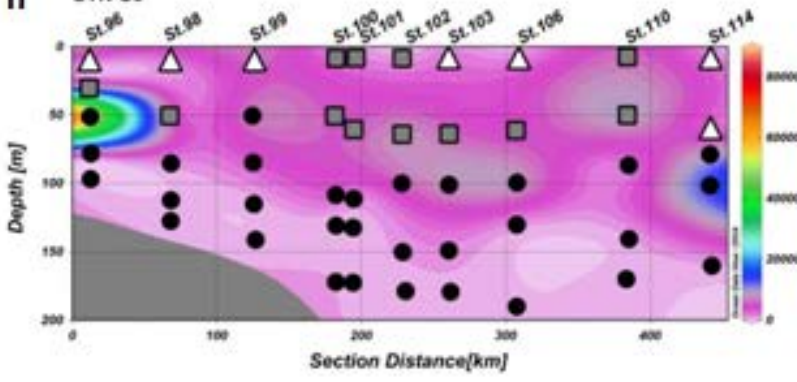

